\title{
Optimization of Demand Side Management and DG Placement in the Distribution System with Demand Response
}

\author{
Subramanya K, M S Nagaraj
}

\begin{abstract}
In the distribution system, Distribution Generation (DG) plays an vital role and by optimizing the DG the performance and efficiency is improved in the distribution system network. Demand Side Management (DSM) deals with this process of optimizing the DGs in a network. In this paper, a new algorithm is proposed for optimal DSM including the demand response and DG units. The optimal capacity and location of the DGs to be connected in the network are selected using real and reactive power loss and voltage profile. The environmental conditions and economic operation of the system is ensured by optimizing the daily performance of the multiple DG units and grid parameters with and without inclusion of demand response. A non dominated sorting firefly algorithm is used to obtain optimization of the functions and decision making fuzzy system is used to decide the best possible scenario from the list of optimized solutions. It is tested with IEEE 33 bus system. The validity of the proposed DSM methodology is verified with the simulation results.
\end{abstract}

Keywords: Demand side management, Distributed Generation, Demand Response, Non dominated Sorting Firefly Algorithm, fuzzy decision making.

\section{INTRODUCTION}

$\mathrm{D}_{\mathrm{i}}$ istribution system bridges the generation of power and consumption of the generated power. The efficiency of the system is improved by Demand side Management process. The DSM involves in planning, implementation and monitoring of the load side activities that impacts the consumption of generated power. The patterns and amount of load consumption is modified in such a manner, so that it improves the performance of the system and also satisfies the consumers. DGs are one of the major factors that influence the distribution system which improves technical environmental and economic indices of the network. The grids are supplied with renewable and nonrenewable means of power generation by DGs to meet with the load demand. The Demand Response is another vital factor which improves the pattern of power consumption from load side in such a way that load demand pattern matches the supply pattern [1-3]. DSM is the set of methodologies to modify the load consumption patterns so that the demand is limited within supply such as peak clipping, load building, flexible load shape, conservation, load shifting and valley filling.

Revised Manuscript Received on October 25, 2020.

* Correspondence Author

Mr. Subramanya K*, Professor and Head, Department of Electrical \& Electronics \& Dean-Training \& Placement, Bapuji Institute of Engineering \&Technology,

Dr. M.S. Nagaraj, Professor and Head, Department of Electrical \& Electronics \& Dean-Training \& Placement, Bapuji Institute of Engineering \&Technology,

(C) The Authors. Published by Blue Eyes Intelligence Engineering and Sciences Publication (BEIESP). This is an open access article under the CC BY-NC-ND license (http://creativecommons.org/licenses/by-nc$\mathrm{nd} / 4.0 /$ )
It encourages the consumers to reduce the energy consumption during peak hours and to shift the usage of energy during off-peak durations [4]. The DSM methods are shown in Fig. 1.

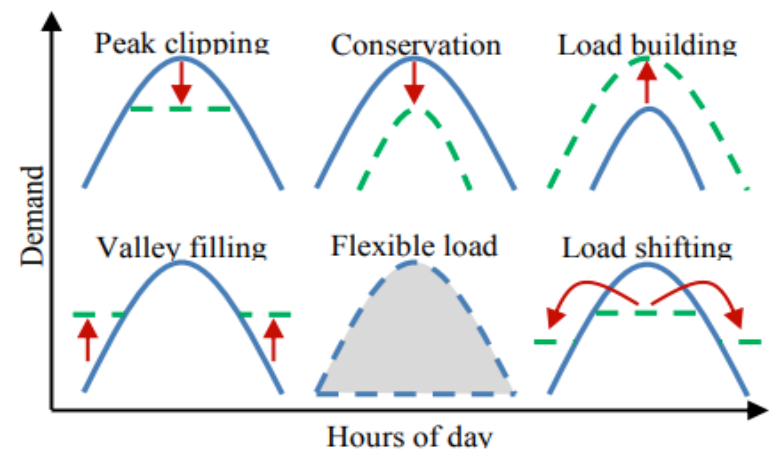

Fig 1 Demand Side Management (DSM) methods Various studies are made for DSM around the world in recent years. A new technique is proposed in DSM through spatial and temporal method [5]. The daily energy losses and operating cost is minimized in the above mentioned technique. The capacity and quick response functionality of different resources such as Electric vehicle DGs, etc., are developed for DSM and studied [6]. In [7], a new DSM algorithm is developed based on direct load control approach to conduct peak shaving. In this, during DSM time variant renewable DGs are considered. A DSM method is applied for building energy systems along with thermal storage systems [8]. Renewable sources with various penetrations and various types of buildings are taken into consideration to yield more reliable outcomes. An intelligent energy management framework is proposed to In this paper, the best location for DG units is optimized along with the capacity of power generation by these DGs using non dominated sorting firefly algorithm (NSFA). The active and reactive power loss and voltage profile are considered for optimizing the capacity and location of the DGs. It also optimizes the day to day performance of the DGs and grid system with and without demand response. Here, the economic and environmental factors are taken as key objectives. The fuzzy decision making technique is used to determine and adapt the best possible solution from pareto optimal solutions. The proposed methodology is applied in IEEE 33 bus system and the results are obtained and analyzed for different conditions.

\section{DISTRIBUTION GENERATION SYSTEMS}

The Distribution Generation consists of two types of energy sources namely

Published By:

Blue Eyes Intelligence Engineering and Sciences Publication

(C) Copyright: All rights reserved.

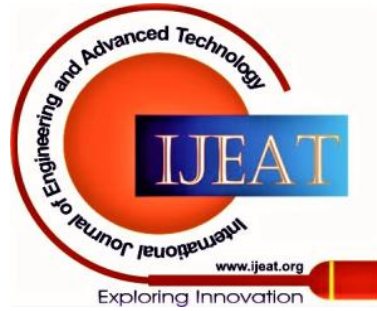




\section{Optimization of Demand Side Management and DG Placement in the Distribution System with Demand Response}

Renewable and Non renewable energy sources. The power generation from non renewable such as diesel generator (DIG), Micro turbine (MT) and Fuel Cell (FC) can be controlled as per the demand by controlling fuel supply. The renewable energy sources like Photo voltaic (PV) and wind turbine (WT) are not predictable as it depends on the weather conditions. The various types of DGs $[15,16]$ are provided as follows:

\section{A. Diesel Generator}

In this the petroleum products such as diesel and Liquid Petroleum Gas (LPG) are used as fuel. The power is generated by the electrical generator coupled with the diesel engine. The power generated is controlled according to the demand in distribution network. In load flow analysis, this is taken as PQ bus as it provides both real and reactive power. In this paper, the power factor is set as 0.85 .

\section{B. Micro Turbine}

It generates both heat energy and electrical energy simultaneously. The fuels used are propane, fuel oil and natural gas. In load flow analysis, it is termed as constant voltage bus as it can inject both reactive and real power into the distribution network.

The PV is one of the renewable energy sources which generate electrical energy from the light energy radiated by the sun. The PV cells are arranged in series and parallel combinations to get the required electrical ratings. The power generated depends on the solar irradiation, efficiency and size of the PV array. This PV acts as P bus as it generates only real power. The power generated by PV array is provided in following equation

$$
P_{P V}=A_{p v} \beta \mu
$$

Where $\mathrm{P}_{\mathrm{PV}}$ is the $\mathrm{PV}$ power generated, $\mathrm{A}_{\mathrm{PV}}$ is area of solar panel, $\beta$ is efficiency of solar panel and $\mu$ is solar irradiance $\left(\mathrm{W} / \mathrm{m}^{2}\right)$.

\section{Wind Turbine}

The wind energy is one of the earliest and purest renewable energy sources. The power generated by wind turbine depends on wind speed, swept area, air density and power coefficient of WT. In load flow analysis, the WT is considered as PQ bus as it generates real power and absorbs reactive power. The real and reactive power relations are provided below:

$$
P_{W T}=\frac{1}{2} \rho A_{W T} V_{W}^{3} C_{P}
$$

Where $\mathrm{P}_{W T}$ is power generated by wind turbine, $\rho$ is Air density, $A_{W T}$ is swept area of wind turbine, $V_{W}$ is wind speed and $C_{P}$ is power coefficient of wind turbine.

$$
Q_{W T}=-\left(0.5+0.04 P_{W T}^{2}\right)
$$

\section{DEMAND RESPONSE}

The demand response is a technique by which the load consumption characteristics are modified according to the supply of power in distribution network. It modifies the power demand instead of modifying supply according to the demand. It consists of time based strategy and incentive based strategy. In this, time based strategy is used as it is easy and also commonly used DR technique. The DR model

\section{Photo Voltaic} equation is provided below:

$$
\begin{aligned}
d(i)=d_{o}(i) \times[ & 1+E(i, i) \frac{P(i)-P_{o}(i)}{P_{o}(i)} \\
& +\sum_{j \neq i}^{24} j \\
& \left.=1 E(i, j) \frac{P(j)-P_{o}(j)}{P_{o}(j)}\right]
\end{aligned}
$$

\section{MULTI OBJECTIVE OPTIMIZATION}

In this, the optimization is done by two following steps:

1. The location and capacity of the multiple DGs are determined in this step by considering loss index and voltage index. The first objective function is provided below:

Firstobjectivefunction: $\min \left(I_{A R L}, I_{V P}\right)$

2. The best schedule for DSM are determined in this step by considering economic index and environmental index. The second objective function is provided below:

Second objectivefunction: $\min \left(I_{\mathrm{OC}}, I_{\mathrm{PE}}\right)$

Where $I_{\mathrm{VP}}$ is voltage index and $I_{\mathrm{ARL}}$ is power loss index. $I_{P E}$ is pollution emission index and $\mathrm{I}_{\mathrm{OC}}$ is operational cost index (economic index) and pollution emission index (environmental index).

\section{A. Loss Index}

The power loss index is the combination of real and reactive power losses. The following equations provide the loss index.

$$
\begin{aligned}
& I_{A R L} \\
& =C_{p} P_{l}+C_{q} Q_{l}
\end{aligned}
$$

Where:

$$
\begin{aligned}
P_{l}=\sum_{i=1}^{N_{b r}} R_{i}\left|I_{i}\right|^{2} & / \sum_{i=1}^{N_{b r}} R_{i}\left|I_{i_{i n s}}\right|^{2}
\end{aligned}
$$

$$
\begin{aligned}
& Q_{l}=\sum_{i=1}^{N_{b r}} X_{i}\left|I_{i}\right|^{2} \\
& / \sum_{i=1}^{N_{b r}} X_{i}\left|I_{i_{\text {ins }}}\right|^{2}
\end{aligned}
$$

\section{B. Voltage Index}

The voltage index indicates the deviation of bus voltages with rated voltage. The network will be stable if the voltage index is nearer to zero. The equation for voltage index calculation is provided below:

$$
\begin{aligned}
I_{V P}=\sum_{i=1}^{n} R_{i}\left(V_{i}-V_{b}\right)^{2} & \\
& / \sum_{i=1}^{n}\left(V_{i_{-} i n s}-V_{b}\right)^{2}
\end{aligned}
$$

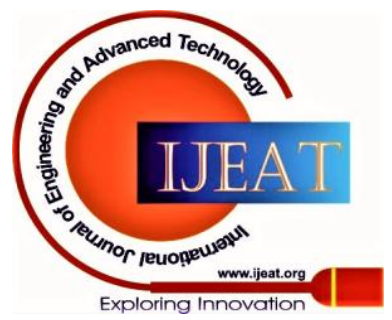




\section{Economic Index}

The operational cost is the major factor in calculating the economic index. The daily cost index is provided in the following equation:

$\mathrm{I}_{\mathrm{OC}}=\mathrm{OC}_{\mathrm{DG}}+\mathrm{OC}_{\text {grid }}+\mathrm{MC}$

Where $O C_{D G}$ is the operational cost of DGs and $O C_{\text {grid }}$ is the operational cost of grid while $M C$ relates to the running and shutting down costs for the ith unit during the $h t h$ hour.

$$
\begin{gathered}
O C_{D G}=\sum_{h=1}^{24}\left[\sum _ { \times C _ { D G _ { i } } ) ] } ^ { n _ { D G } } \left(P_{D G_{i}}(h)\right.\right. \\
O C_{\text {grid }}=\sum_{h=1}^{24}\left[\left(P_{\text {grid }}(h)\right.\right. \\
\times M P(h)] \\
\times C=\sum_{h=1}^{24}\left[\sum _ { i = 1 } ^ { n _ { \text { unit } } } \left(C_{S S_{i}} \times \mid M_{\text {unit }_{i}}(h)\right.\right. \\
-M_{\text {unit }}(h \\
-1) \mid)]
\end{gathered}
$$

\section{PROPOSED HYBRID OPTIMIZATION ALGORITHM}

The constraints that are to be followed while the proposed optimization algorithm is applied on the IEEE 33 bus system are provided below:

1. The permitted range of bus voltages are within the following limits:

$$
\begin{aligned}
& V_{\min } \leq V_{i} \\
& \leq V_{\max }
\end{aligned}
$$

2. The DG units which is connected to the distribution network should supply the power within the following limits:

$$
P_{D G}{ }^{\text {min }} \leq P_{D G_{-} i} \leq P_{D G} \max
$$

3. The sum of power generated by the grid and DGs should satisfy the load demand in the distribution system with losses is taken into account.

$$
\begin{aligned}
\sum_{i=1}^{n_{D G}} P_{D G_{-} i}+P_{\text {grid }} & \\
& =\sum_{j=1}^{n} P_{\text {demand }_{j}} \\
& +\sum_{i=1}^{N_{b r}} P_{\text {loss }_{i}}(17)
\end{aligned}
$$

4. The charging and discharging characteristics of Energy Storage Systems (ESS) should meet the following limitations for each hour.

$$
\begin{aligned}
& W_{E S S}(t) \\
& =W_{E S S}(t-1)+\eta_{\text {charge }} P_{\text {charge }}(t) \\
& -\frac{P_{\text {discharge }}}{\eta_{\text {discharge }}} \\
& \quad W_{E S S \_m i n} \leq W_{E S S}(t) \leq W_{E S S_{-} \max } \\
& P_{\text {charge }}(t) \\
& \leq P_{\text {charge_max }} \\
& \quad P_{\text {discharge }}(t) \leq P_{\text {discharge_max }}
\end{aligned}
$$

In order to optimize the technical, environmental and economic indices, the NSFA and fuzzy logic decision making techniques are combined. Both techniques are explained below:

\section{A. Non dominated Sorting Firefly Algorithm}

In this, each firefly possess absorption quality and the worms move towards the firefly of higher absorption power. The most attracted firefly is selected which is considered as optimal solution. In this changes in light intensity and attractiveness are considered as two variables. The quality of attractiveness is a relative quantity which depends on other fireflies and also their distances. In this, the updated location of each particle (firefly) when $\mathrm{j}^{\text {th }}$ firefly is brighter than $\mathrm{i}^{\text {th }}$ firefly is given below:

$$
x_{\imath}=x_{\imath}+\beta_{o} e^{-\gamma r^{2}}\left(x_{j}-x_{l}\right)+\alpha \varepsilon_{l}
$$

Where, $\beta 0$ is the attractiveness when $\mathrm{r}=0$ and $\mathrm{r}$ is the distance between any two fireflies $i$ and $j, \gamma$ is the absorption coefficient $(\mathrm{\gamma}=1)$, and $\alpha$ being the random parameter. In more complex issues, the multi objective algorithms are more reliable than the single objective algorithms. The firefly algorithm is modified into multi objective algorithm to provide the optimization according to the objective functions. In this, during optimization, the particles of higher values remain while others are removed using non dominant sorting and crowded distance sorting. The procedure model of NSFA is provided in Fig 2.

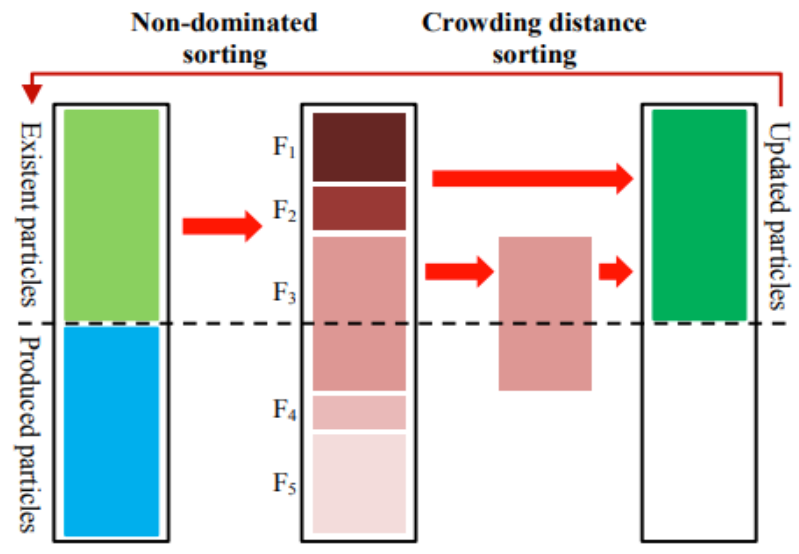

Fig 2 Procedure block diagram of Non Sorted Firefly Algorithm(NSFA)

The particles are compared with all other particles and non dominated fronts or pareto optimal fronts sorts the particles in the proposed method.

\section{B. Fuzzy Decision Making}

Based on the particle selected, fuzzy control provides the optimal solution in the pareto optimal front. The membership functions of the fuzzy control are provided below:

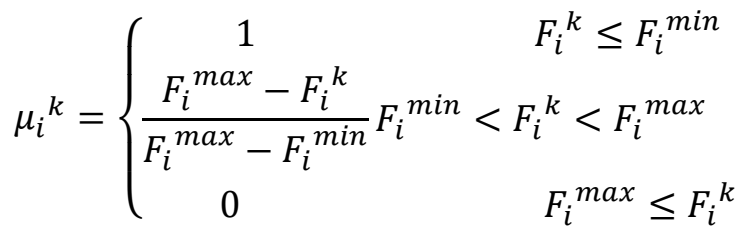

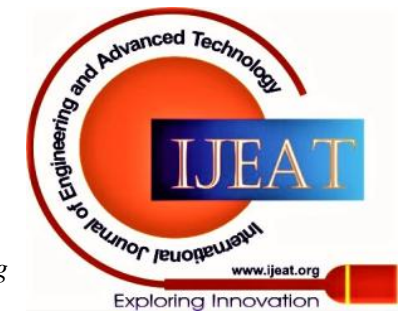




\section{Optimization of Demand Side Management and DG Placement in the Distribution System with Demand \\ Response}

The normalized value of the membership function is calculated by the following equation:

$$
\begin{aligned}
& \mu^{k} \\
& =\frac{\sum_{i=1}^{N O} \mu_{i}{ }^{k}}{\sum_{k=1}^{N K} \sum_{i=1}^{N O} \mu_{i}{ }^{k}}
\end{aligned}
$$

The optimal solution is selected by finding the maximum value of $\mu_{\mathrm{k}}$. The best solution among the pareto front is shown in the following Fig 3

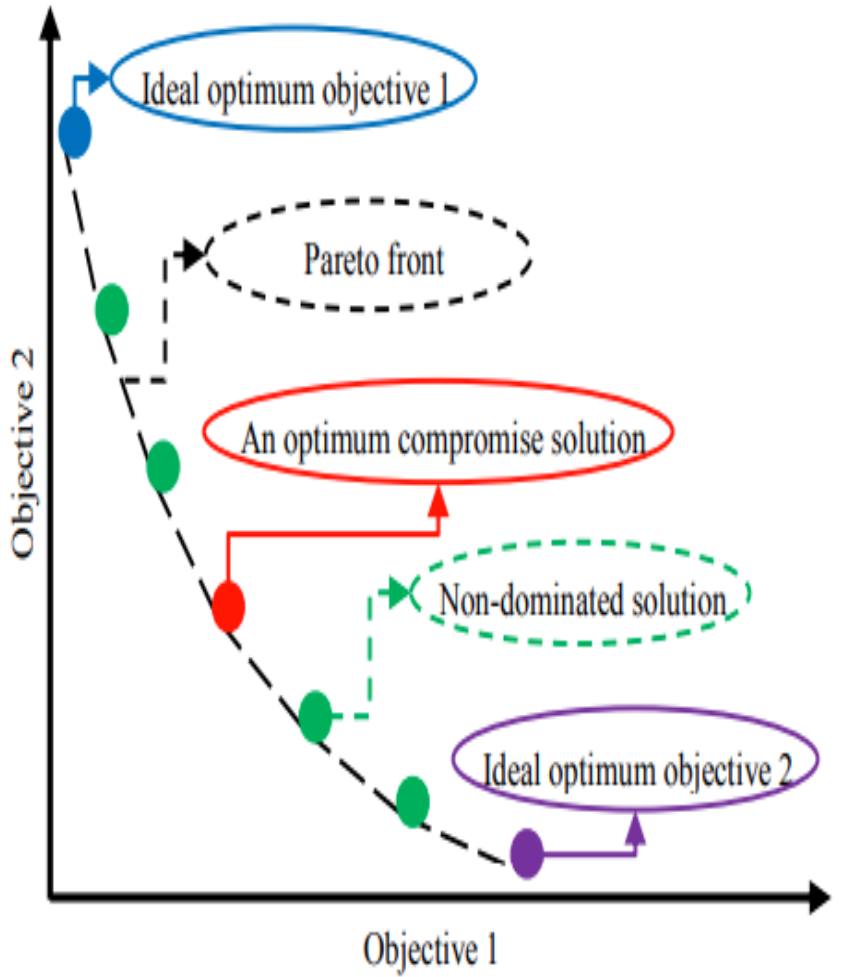

Fig 3 Optimal compromise solution from fuzzy membership functions

The technical indices such as power loss index and voltage indices are optimized by optimizing the location and capacity of the DGs by combining NSFA and fuzzy decision making system as shown in Fig 4. The environmental and economic indices are optimized by the NSFA and fuzzy decision making technique. The DSM for the distribution network is done with and without DR. The algorithm to find the optimal schedule is provided in the flowchart shown in Fig 5.

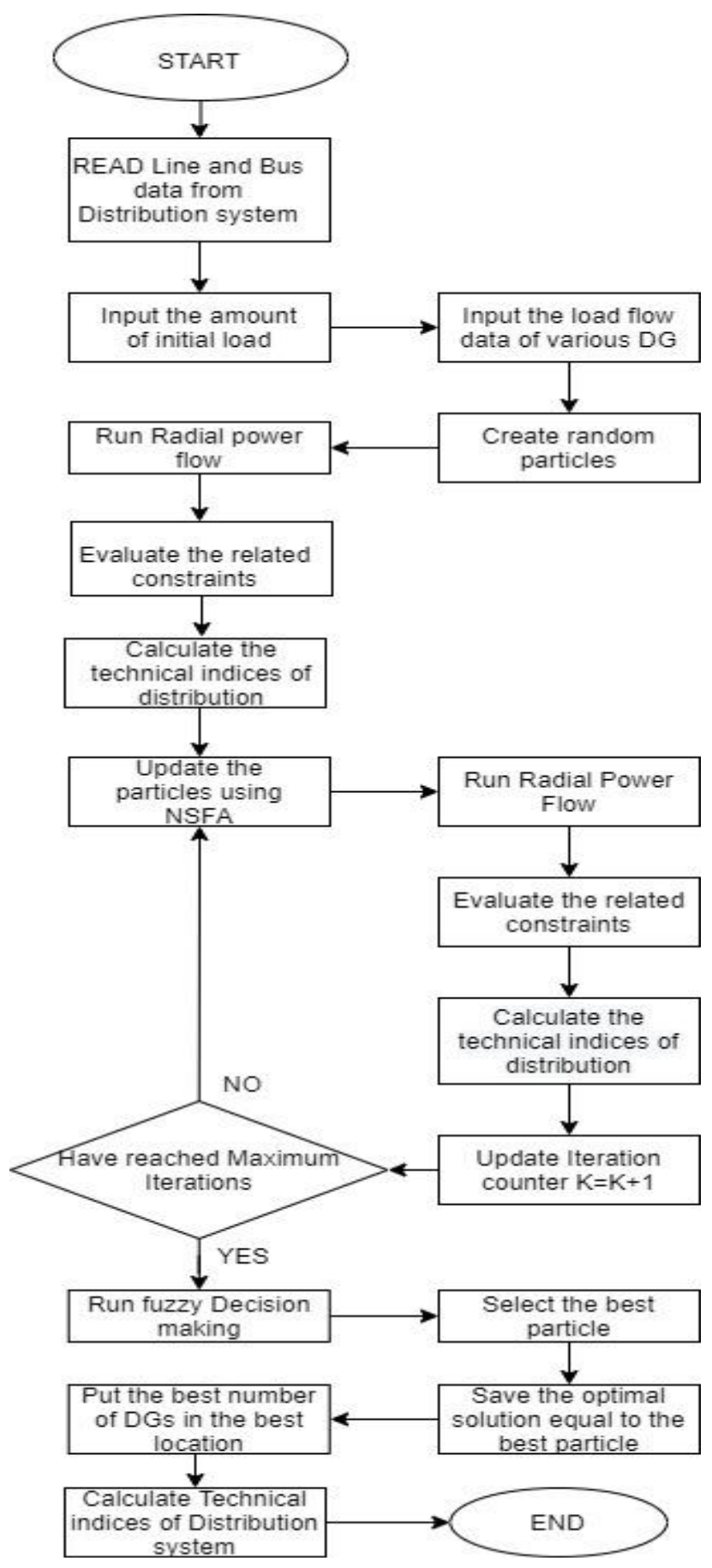

Fig 4 Flowchart to find optimal location and capacity of DGs

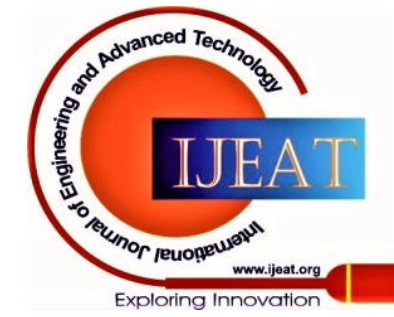




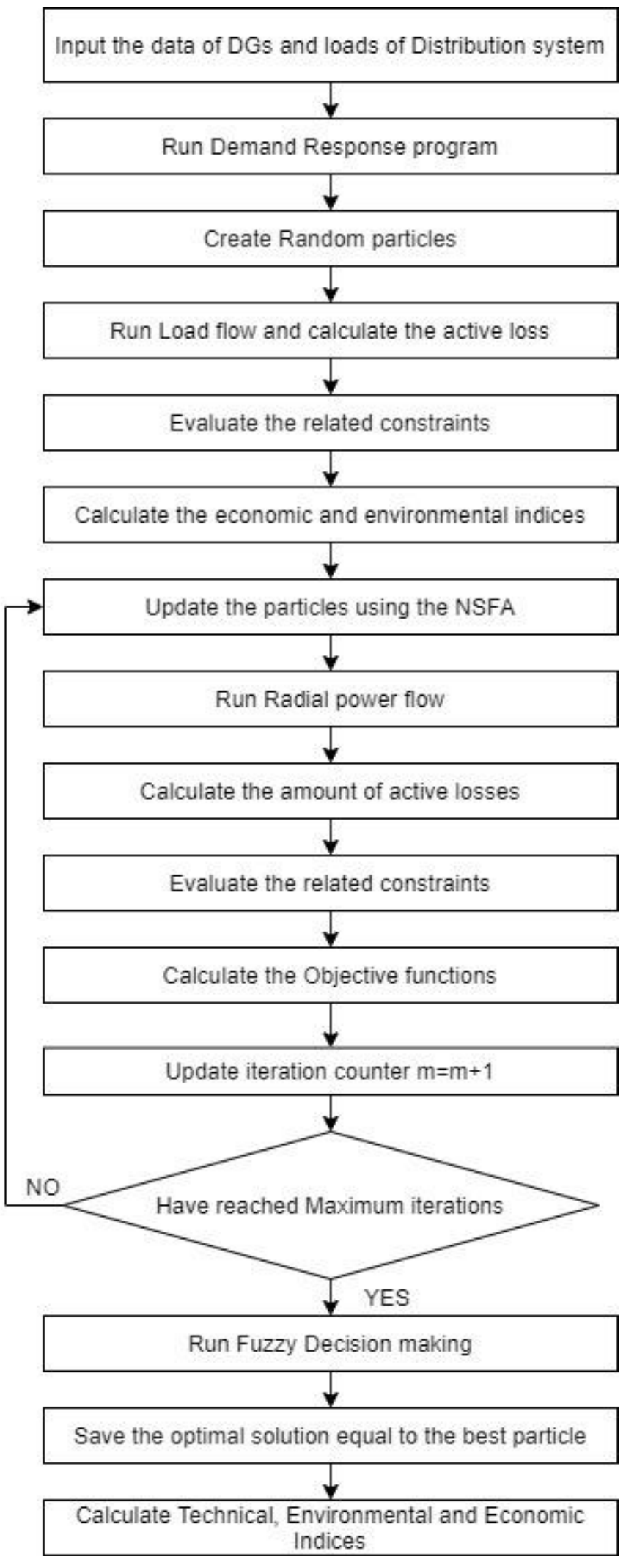

Fig 5 Flowchart to find optimal schedule for the DSM

\section{SIMULATION SETUP \& RESULTS}

The proposed hybrid algorithm is applied in IEEE 33 bus system. Nearly $40 \%$ of the consumers are engaged in this DR program. The maximum and minimum limits of the DG units are $4000 \mathrm{KW}$ and $100 \mathrm{KW}$ respectively. The step value for each new DG connected to the network is having minimum capacity. The daily load graph of the distribution network is provided in Fig 6.

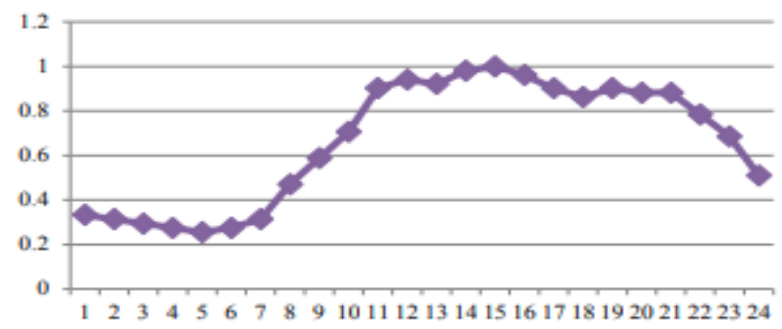

Fig 6 Daily Load graph of Distribution system The hourly generation of PV and WT is shown in Fig 7 provided below:

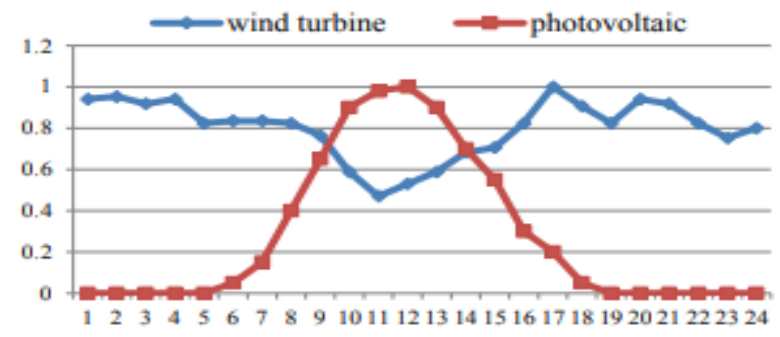

Fig 7 Power Generation of PV and WT per hour The maximum and minimum of \%SOC of the batteries are termed as $100 \%$ and $10 \%$ respectively. The TABLE 1 consists of information regarding economic and environmental indices for all the DGs.

TABLE 1 Economic information of all sources

\begin{tabular}{|c|c|c|c|}
\hline $\begin{array}{c}\text { SI } \\
\text { no }\end{array}$ & DG Type & $\begin{array}{c}\text { Power Cost } \\
\text { (\$/kwh) }\end{array}$ & $\begin{array}{c}\text { Stat-up and } \\
\text { shut down cost }\end{array}$ \\
\hline 1 & DIG & 1.172 & 0.35 \\
\hline 2 & PV & 5.168 & 0 \\
\hline 3 & WT & 2.146 & 0 \\
\hline 4 & MT & 0.914 & 1.92 \\
\hline
\end{tabular}

The real time market price in distribution network is shown in Fig 8.

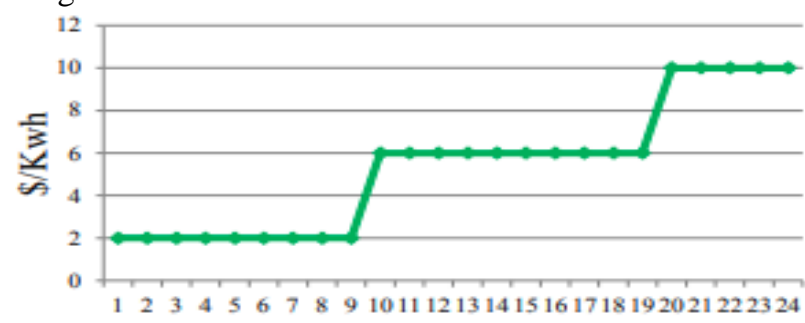

Fig 8 Real time Market Price

\section{IEEE 33 Bus System}

The proposed algorithm is implemented in the IEEE 33 bus system. The single line diagram of the above mentioned bus system is shown in Fig 9.
Blue Eyes Intelligence Engineering and Sciences Publication

(c) Copyright: All rights reserved.

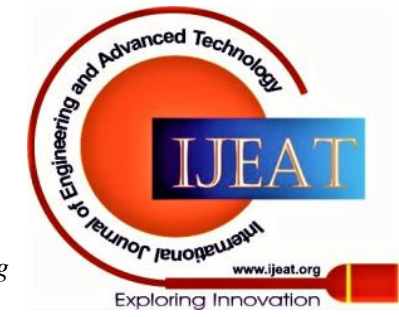




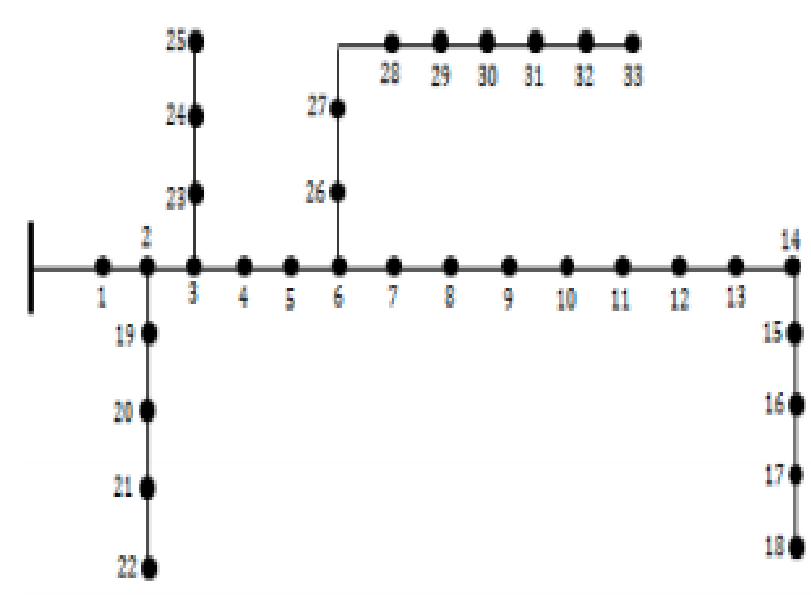

Fig 9 Single line diagram of IEEE 33 bus system Initially, the optimal location and capacity of the DGs are determined by the proposed algorithm. The optimum location and capacity of the DG units are tabulated in Table II.

TABLE II Optimum Location and capacity of DGs in IEEE 33 bus system

\begin{tabular}{|c|c|c|c|}
\hline SI no & DG Type & Location (bus) & Capacity (MW) \\
\hline 1 & DIG & 30 & 1.7 \\
\hline 2 & PV & 28 & 0.9 \\
\hline 3 & WT & 06 & 1.2 \\
\hline
\end{tabular}

The technical indices are determined before and after placing the DGs in 33 bus system and tabulated in Table III for comparison.

\begin{tabular}{|c|c|c|c|}
\hline \multicolumn{1}{|c|}{ TABLE III Technical Indices of 33 Bus System } \\
no & Indices & $\begin{array}{c}\text { Before } \\
\text { placement } \\
\text { of DGs }\end{array}$ & $\begin{array}{c}\text { After } \\
\text { placement } \\
\text { of DGs }\end{array}$ \\
\hline 1 & $\begin{array}{c}\text { Active power } \\
\text { Loss (MW) }\end{array}$ & 0.2025 & 0.0250 \\
\hline 2 & $\begin{array}{c}\text { Reactive power } \\
\text { Loss (MW) }\end{array}$ & 0.1351 & 0.0189 \\
\hline 3 & $\begin{array}{c}\text { Voltage Profile } \\
\text { (Pu) }\end{array}$ & $\begin{array}{c}0.91301 \text { (bus } \\
18)\end{array}$ & $0.9861(33)$ \\
\hline
\end{tabular}

From the above tables we can conclude that the placement of DGs in the bus system improves the performance of the system by reducing the real and reactive power losses and also improves the voltage profile.

The scheduling was done by the proposed algorithm after finding the location and capacity of DGs connected.The optimal scheduling of energy sources without demand response is shown in Table IV.

TABLE IV Scheduling of Energy Sources without Demand Response

\begin{tabular}{|l|l|l|l|l|l|l|}
\hline Hrs & DIG & MT & PV & WT & ESS & Grid \\
\hline 1 & 0 & 1.0493 & 0 & 0 & 0.1889 & 0 \\
\hline 2 & 0 & 0.9023 & 0 & 0.0181 & 0.245 & 0 \\
\hline 3 & 0 & 0.9889 & 0 & 0 & 0.1037 & 0 \\
\hline 4 & 0 & 1.1 & 0 & 0 & -0.0802 & 0 \\
\hline 5 & 0 & 0.5198 & 0 & 0 & 0.4271 & 0 \\
\hline 6 & 0.002 & 1.1 & 0 & 0 & -0.0822 & 0 \\
\hline 7 & 0 & 0.6654 & 0 & 0 & 0.5 & 0 \\
\hline
\end{tabular}
Tand response is shown in Table $\mathrm{V}$.

In this, non renewable sources provides two thirds of the total demand and remaining was provided by renewable energy sources. In the renewable sources, WT provides the power twice that of PV. The grid will act as backup source if the DGs are failed to satisfy the demands. The operational cost of the distribution network is reduced along with loss indices and pollution emission is also reduced.

The technical, environmental and economic indices without

Bus system without Demand Response

\begin{tabular}{|l|l|l|l|l|}
\hline Hrs & PLI & QLI & VPI & OCI \\
\hline 1 & 0.039 & 0.0166 & 0.0379 & 21.824 \\
\hline 2 & 0.0337 & 0.0131 & 0.0348 & 20.951 \\
\hline 3 & 0.022 & 0.0053 & 0.0282 & 18.911 \\
\hline 4 & 0.026 & 0.008 & 0.0304 & 19.639 \\
\hline 5 & 0.0182 & 0.0028 & 0.026 & 18.183 \\
\hline 6 & 0.0167 & 0.0018 & 0.0251 & 17.893 \\
\hline 7 & 0.0167 & 0.0018 & 0.0251 & 17.893 \\
\hline 8 & 0.0145 & 0.0003 & 0.0239 & 17.455 \\
\hline 9 & 0.039 & 0.0166 & 0.0379 & 21.824 \\
\hline 10 & 0.0755 & 0.0409 & 0.0587 & 26.924 \\
\hline 11 & 0.0588 & 0.0298 & 0.0492 & 24.74 \\
\hline 12 & 0.0814 & 0.0449 & 0.0621 & 27.652 \\
\hline 13 & 0.1208 & 0.0712 & 0.0847 & 32.021 \\
\hline 14 & 0.0875 & 0.0489 & 0.0656 & 28.381 \\
\hline 15 & 0.1069 & 0.0619 & 0.0767 & 30.565 \\
\hline 16 & 0.1002 & 0.0575 & 0.0729 & 29.657 \\
\hline 17 & 0.0755 & 0.0409 & 0.0587 & 26.924 \\
\hline 18 & 0.1002 & 0.0575 & 0.0729 & 29.837 \\
\hline 19 & 0.1137 & 0.0665 & 0.0806 & 31.293 \\
\hline 20 & 0.0588 & 0.0298 & 0.0492 & 24.74 \\
\hline 21 & 0.0588 & 0.0298 & 0.0492 & 24.74 \\
\hline 22 & 0.0642 & 0.0334 & 0.0522 & 25.468 \\
\hline & & & & \\
\hline
\end{tabular}




\begin{tabular}{|l|l|l|l|l|}
\hline 23 & 0.0642 & 0.0334 & 0.0522 & 25.468 \\
\hline 24 & 0.0755 & 0.0409 & 0.0587 & 26.924 \\
\hline
\end{tabular}

The demand response is also added with the DSM and the scheduling of DGs of different sources with ESS and grid is provided in Table VI.

TABLE VI Scheduling of Energy Sources with Demand Response

\begin{tabular}{|l|l|l|l|l|l|l|}
\hline Hrs & DIG & MT & PV & WT & ESS & Grid \\
\hline 1 & 0 & 1.0944 & 0 & 0.6785 & 0.4122 & 0 \\
\hline 2 & 0.2023 & 1.1 & 0 & 0.7623 & 0.0333 & 0 \\
\hline 3 & 0 & 1.1 & 0 & 0.6616 & 0.1323 & 0 \\
\hline 4 & 0.0005 & 1.1 & 0 & 0.6086 & 0.2576 & 0 \\
\hline 5 & 0.1498 & 1.1 & 0 & 0.6588 & -0.1178 & 0.0303 \\
\hline 6 & 0 & 1.1 & 0 & 0.1921 & 0.5 & 0 \\
\hline 7 & 0.0689 & 1.1 & 0 & 0.6682 & -0.0536 & 0.0086 \\
\hline 8 & 0 & 1.0857 & 0 & 0.1626 & 0.5 & 0 \\
\hline 9 & 0.1911 & 1.1 & 0.39 & 0.6118 & -0.1077 & 0 \\
\hline 10 & 0.0847 & 1.1 & 0.54 & 0.4706 & 0.5 & 0 \\
\hline 11 & 0.565 & 1.0578 & 0.34 & 0.675 & -0.178 & 0.017 \\
\hline 12 & 0.14 & 1.1 & 0.6 & 0.4235 & 0.5 & 0.0045 \\
\hline 13 & 0.954 & 1.0599 & 0.589 & 0.62 & -0.069 & 0.051 \\
\hline 14 & 0.2679 & 1.1 & 0.42 & 0.5459 & 0.5 & 0.0071 \\
\hline 15 & 1.1669 & 1.1 & 0.2815 & 0.5647 & -0.0538 & 0 \\
\hline 16 & 0.5477 & 1.1 & 0.18 & 0.6588 & 0.5 & 0 \\
\hline 17 & 0.7837 & 1.1 & 0.12 & 0.8 & -0.1117 & 0.0033 \\
\hline 18 & 0.6318 & 1.1 & 0.03 & 0.7247 & 0.5 & 0 \\
\hline 19 & 0.718 & 0.986 & 0.564 & 0.755 & -0.083 & 0.1921 \\
\hline 20 & 0.1238 & 1.1 & 0 & 0.753 & 0.5 & 0 \\
\hline 21 & 1.123 & 1.0288 & 0 & 0.706 & -0.389 & 0.008 \\
\hline 22 & 0.2908 & 1.1 & 0 & 0.6588 & 0.5 & 0 \\
\hline 23 & 0.8981 & 1.1 & 0 & 0.6023 & -0.0519 & 0.0011 \\
\hline 24 & 0.5302 & 1.1 & 0 & 0.64 & 0.425 & 0 \\
\hline 76 & & 0 & 0 & 0 \\
\hline
\end{tabular}

The technical, environmental and economic indices with demand response is shown in Table VII.

TABLE VII Technical and Economic indices of IEEE 33 Bus system with Demand Response

\begin{tabular}{|l|l|l|l|l|}
\hline Hour & PLI & QLI & VPI & OCI \\
\hline 1 & 0.0294 & 0.0187 & 0.0211 & 2.9244 \\
\hline 2 & 0.0148 & 0.0086 & 0.0125 & 2.758 \\
\hline 3 & 0.0187 & 0.0112 & 0.0142 & 2.4573 \\
\hline 4 & 0.021 & 0.0129 & 0.0158 & 2.5371 \\
\hline 5 & 0.0095 & 0.0049 & 0.0088 & 2.3019 \\
\hline 6 & 0.0154 & 0.0089 & 0.0124 & 2.016 \\
\hline 7 & 0.0122 & 0.0067 & 0.0103 & 2.2831 \\
\hline 8 & 0.0141 & 0.0079 & 0.0116 & 1.9396 \\
\hline 9 & 0.0092 & 0.0043 & 0.0048 & 4.2203 \\
\hline 10 & 0.0282 & 0.0174 & 0.0122 & 5.5033 \\
\hline 11 & 0.004 & 0.0008 & 0.003 & 4.4226 \\
\hline 12 & 0.027 & 0.0166 & 0.0106 & 5.7861 \\
\hline 13 & 0.0099 & 0.0053 & 0.0016 & 6.285 \\
\hline 14 & 0.0229 & 0.0136 & 0.0127 & 5.2736 \\
\hline 15 & 0.0093 & 0.0055 & 0.0031 & 4.7848 \\
\hline 16 & 0.0203 & 0.0123 & 0.0152 & 4.5893 \\
\hline 17 & 0.0083 & 0.0045 & 0.0066 & 3.9234 \\
\hline & & & & \\
\hline
\end{tabular}

\begin{tabular}{|l|l|l|l|l|}
\hline 18 & 0.0238 & 0.0154 & 0.0185 & 4.0541 \\
\hline 19 & 0.0123 & 0.0066 & 0.0046 & 6.3891 \\
\hline 20 & 0.0333 & 0.0214 & 0.0242 & 3.3644 \\
\hline 21 & 0.0106 & 0.0068 & 0.0041 & 3.0165 \\
\hline 22 & 0.0257 & 0.0162 & 0.0201 & 3.358 \\
\hline 23 & 0.0089 & 0.0054 & 0.0063 & 3.1008 \\
\hline 24 & 0.0195 & 0.0122 & 0.0161 & 3.4827 \\
\hline
\end{tabular}

In the above table, the indices are improved when DSM is implemented with demand response compared to previous responses. The load variation graph of IEEE 33 bus system after adding DR program is provided in Fig 10.

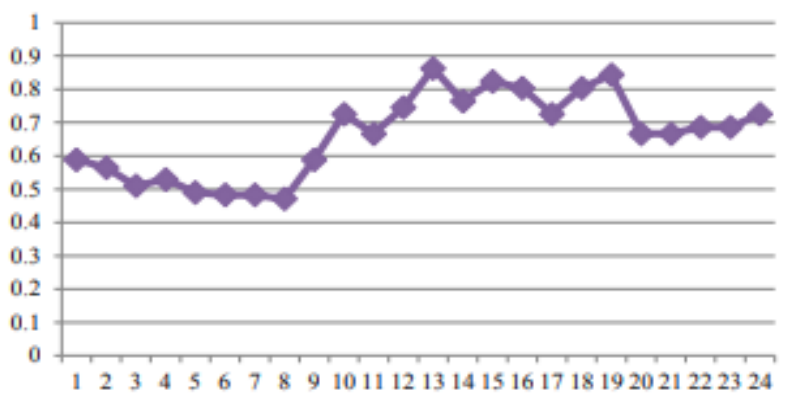

Fig 10 Load variation of IEEE 33 bus system with DR response

The performance of distribution system after applying DSM with demand response program is shown in Fig 11.

9 without TOU $\square$ with TOU

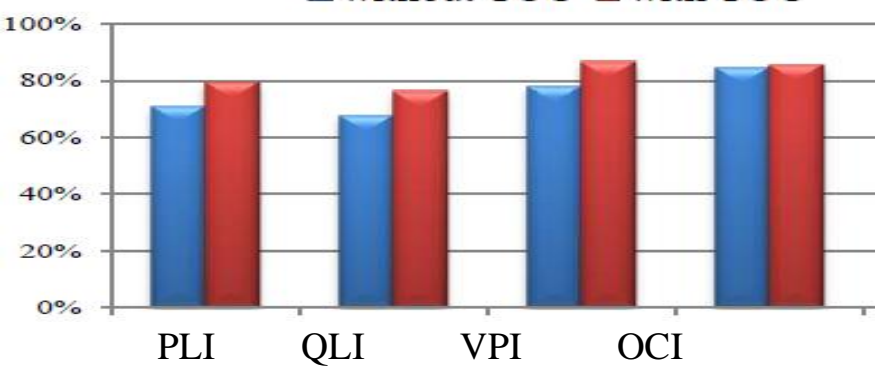

Fig 11 Technical, Economic Indices in IEEE 33 Bus system with DR response

VII. CONCLUSION

The optimal capacity and location of the DGs to be connected in the network were selected using real and reactive power loss and voltage profile. The environmental conditions and economic operation of the system was ensured by optimizing the daily performance of the multiple DG units and grid parameters with and without inclusion of demand response. A hybrid optimization algorithm was developed which consists of non dominated sorting firefly algorithm which was used to obtain optimization of the functions and decision making fuzzy system which was used to decide the best possible scenario from the list of optimized solutions. It was tested with IEEE 33 bus system. In the above mentioned distribution network, the non renewable sourced DGs provide stability to the system while renewable sourced DGs provide improvement in environmental indices. The efficiency of the distribution system was further increased with demand response program which encourages the participation of consumers.

Published By:

Blue Eyes Intelligence Engineering and Sciences Publication

(C) Copyright: All rights reserved.

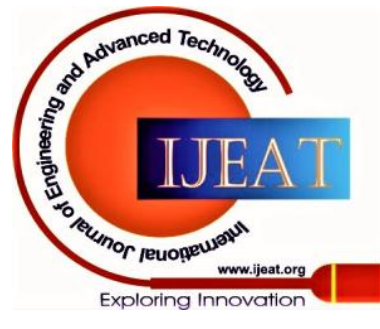




\section{Optimization of Demand Side Management and DG Placement in the Distribution System with Demand Response}

\section{REFERENCES}

1. L. Gelazanskas, A. Gamage, "Demand side management in smart grid: a review and proposals for future direction", Sustainable Cities Soc., vol. 11, pp. 22-30,2014.

2. M. Behrangrad, "A review of demand side management business models in the electricity market", Renewable Sustainable Energy Rev., vol. 47, pp. 270-283, 2015.

3. H. Shayeghi, M. Alilou, "Application of multi objective hfapso algorithm for simultaneous placement of DG, capacitor and protective device in radial distribution network", J. Oper. Autom. Power Eng., vol. 3, p.131-146, 2015.

4. E. Heydarian, H. A. Aalami, "Multi objective scheduling of utilityscale energy storages and demand response programs portfolio for grid integration of wind power", J. Oper. Autom. Power Eng., vol. 4, pp. 104-116, 2016.

5. Sanjeeva Kumar R A,Kavya Prayaga, "A Weighted Sum of MultiObjective Function based Reliability Analysis with the Integration of Distributed Generation",International Journal of Engineering and Advanced Technology(IJEAT),Volume-9 Issue-4,April 2020.

6. M. Wang, Y. Ting, Y. Mu, H. Jia, L Shiguang, "A unified management and control model of demand-side resources", Energy Procedia, vol. 105, pp. 2935-2940, 2017.

7. F. Verrilli, G. Gambino, S. Srinivasan, G. Palmieri, C. Vecchio, L. Glielmo, "Demand side management for heating controls in microgrids", Int. Fed. Autom. Control, pp. 611- 616, 2016.

8. D. Müller, A. Monti, S. Stinner, T. Schlosser, Th. Schütz, P. Matthes, H. Wolisz, Ch. Molitor, H. Harb, R. Streblow, "Demand side management for city districts", Build. Environ., vol. 91, pp. 283-293, 2015.

9. Sanjeeva Kumar R A, Sudarshana Reddy H R and Ananthapadmanabha T, "Enhancement of Power Quality in Distribution System by Optimal Integration of Distributed Generators Using Hybrid Flower Pollination Algorithm", in International Journal of Electrical Engineering and Technology(IJEET), Volume 9, Issue 3, May-June 2018, Pp. 146-153.

10. H. Li, Q. An, B. Yu, J. zhao, L. Cheng, Y. Wang, "Strategy analysis of demand side management on distributed heating driven by wind power", Energy Procedia, vol. 105, pp. 2207-2213, 2017.

11. Z. Wu, H. Tazvinga, X. Xia, "Demand side management of photovoltaic-battery hybrid system", Appl. Energy,vol. 148, pp. 294304, 2015.

12. Sanjeeva Kumar R A, Sudarshana Reddy H R and Ananthapadmanabha T, "Analytical Approach for Optimal Placement of Distributed Generators in Power System", in International Journal of advent in research Technologies (IJRAT), July 2018, Volume 6, Issue 7.

13. K. Ma, C. Wang, J. Yang, Z. Tian, X. Guan, "Energy management based on demand-side pricing: a supermodular game approach", IEEE Access, vol. 5, pp. 18219-18228, 2017.

14. Sanjeeva Kumar R A, Sudarshana Reddy H R and Ananthapadmanabha T, "Multi-Objective Based Analytical Approach For Optimal Placement Of Distributed Generators In Power System", in Journal of Emerging Technologies and Innovative Research, Vol5, Issue 7, page no.605-609, July 2018,

15. M. Aman, G. Jasmon, A. Bakar, H. Mokhlis, "A new approach for optimum simultaneous multi-DG distributed generation unit's placement and sizing based on maximization of system loadability using HPSO (hybrid particle swarm optimization) algorithm", Energy, vol. 66, pp. 202-215, 2014.

16. H. Bagheri, M. H. Ali, and M. Rizwan, "Novel hybrid fuzzyintelligent water drops approach for optimal feeder multi objective reconfiguration by considering multiple-distributed generation", J. Oper. Autom. Power Eng., vol. 2, pp. 91-102, 2014

17. M. Moghaddam, A. Abdollahi, M. Rashidinejad, "Flexible demand response programs modeling in competitive electricity markets", Appl. Energy, vol. 88, pp. 3257-3269, 2011.

18. Kavya prayaga, Sanjeeva Kumar R APower Quality Analysis Of Distribution System Using Hybrid Intelligent Algorithm By Optimal Integration Of Dg's Journal of Emerging Technologies and Innovative Research, Vol 06, Issue 5, May 2019,[19] Xin-she. Yang, "Firefly algorithms for multimodal optimization", arXiv: 1003.1466v1 [math.OC], , (7 Mar 2010).

19. K. Deb, A. Pratap, S. Agarwal, T. Meyarivan, "A fast and elitis multiobjective genetic algorithm: NSGA-II", IEEE Trans. Evol. Comput., vol. 6, pp. 182-197, 2002.

\section{AUTHORS PROFILE}

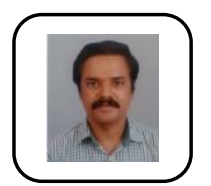

Mr. Subramanya K has 20 years of experience in the field of industry, handling Projects, Electrical \&Mechanical maintenance. Also expertise in energy retrofits. He has completed his M.Tech in VLSI design and embedded systems From Visvesvaraya Technological University. He has published research papers in National conferences. His research interest is in the area of Demand side Managementand Distributed Generation, power quality studies and electrical safety system analysis.

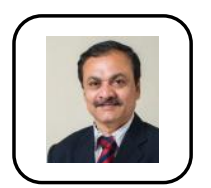

Dr. M.S. Nagaraj has completed his Ph.D from Visvesvaraya Technological University, 2008. He has more than 35 years of experience. Currently working as Professor and Head, Department of Electrical \& Electronics \& Dean-Training \& Placement, Bapuji Institute of Engineering \&Technology, Davanagere. He is a recognized research guide in VTU. He has published many papers in National and International conferences and journals. His research interests are Electrical Load forecasting, Reactive power management, Artificial Neural Network, Fuzzy Logic, Demand side management, Power transmission, Smart grid, Energy Auditing, power quality studies, Micro grid and renewable power integration. He is life time member of ISTE \& Member of Institution of Engineers

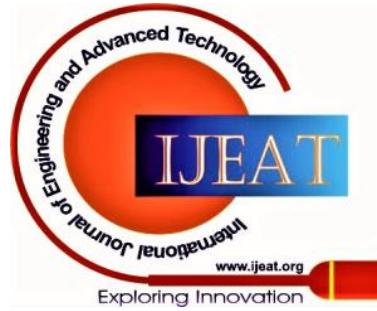

